VNU Journal of Science: Legal Studies Journal homepage: https://js.vnu.edu.vn/LS

Original Article

\title{
Due Process of Law in Russian Federation Law: Perception and Core Issues
}

\author{
Mai Van Thang* \\ VNU School of Law, 144 Xuan Thuy, Cau Giay, Hanoi, Vietnam \\ Received 15 October 2020 \\ Revised 20 November 2020; Accepted 18 December 2020
}

\begin{abstract}
This article explains the reasons for the lack of popularity of the term "due process of law" in the Russian current legal system. Nevertheless, all fundamental aspects of this principle included perception, core issues, and requirements that have been shown in a relatively complete and comprehensive way under another name with various levels, forms of expression, and its compliance. By Russia's case study, the author affirms that due process of law is necessary not only in the procedure proceedings that take place before the judicial decisions to be made but also in the implementation of decisions and judgments given by courts and other entities. Above all, due process of law would maximize its efficiency when it is nourished in an appropriate ecosystem.
\end{abstract}

Keywords: Due process of law, Russian Federation, constitution, forms of proceedings.

\footnotetext{
* Corresponding author.

E-mail address: thangmv@vnu.edu.vn

https://doi.org/10.25073/2588-1167/vnuls.4330
} 


\title{
Trình tự công bằng trong pháp luật Liên bang Nga: Nhận thức và nội dung cốt lõi
}

\author{
Mai Văn Thắng* \\ Khoa Luật, Đại học Quốc gia Hà Nội, 144 Xuân Thủy, Cầu Giấy, Hà Nội, Việt Nam \\ Nhận ngày 15 tháng 10 năm 2020 \\ Chỉnh sửa ngày 20 tháng 11 năm 2020; Chấp nhận đăng ngày 18 tháng 12 năm 2020
}

\begin{abstract}
Tóm tắt: Bài viết luận giải vì sao ở Nga không phổ biến thuật ngữ "due process of law", nhưng nhận thức, nội dung, các yêu cầu của nguyên tắc ây vẫn được thể hiện tương đối đầy đủ, toàn diện trong hệ thống pháp luật hiện nay dưới tên gọi khác với nhiều cấp độ, hình thức thể hiện, bảo đảm khác nhau. Qua phân tích trường hợp ở Nga, tác giả muốn khẳng định rằng, trình tự công bằng không nên chỉ dừng lại ở các quy trình, thủ tục tố tụng trước phán quyết/quyết định của cơ quan xét xử, mà còn cần cho cả quy trình, thủ tục thi hành các bản án, phán quyết của tòa án, cần cho các thủ tục, quy trình xử lý vi phạm bởi các chủ thể khác không phải là tòa án và hơn tất cả, để ý nghĩa, mục tiêu cao đẹp của trình tự công bằng đạt được rất cần dung dưỡng "hệ sinh thái" phù hợp với nó.
\end{abstract}

Tù khóa: Trình tự công bằng, Liên bang Nga, hiến pháp, các hình thức tố tụng.

\section{Dẫn nhập}

Trình tự pháp luật công bằng [1] như là nguyên tắc pháp lý không được biết đến rộng rãi ở Nga. Có lẽ là bởi nguyên tắc này được hình thành và phát triển ở truyền thống Thông luật vốn xa lạ với văn hóa pháp luật nước Nga. Nhưng điều này không đồng nghĩa những nội dung cốt lõi của "trình tự không bằng" không hiện hữu trong hệ thống pháp luật quốc gia này.

Sau khi Liên Xô sụp đổ, người Nga bắt đầu xây dựng thể chế cộng hòa pháp quyền dân chủ liên bang [2]. Các giá trị cốt lõi của phân quyền, quyền, tự do của con người cũng như những nguyên tắc phổ quát của luật quốc tế hiện đại đều được ghi nhận, tôn trọng và ở chừng mực nhất định được bảo vệ, bảo đảm, thúc đẩy.

Hiến pháp Liên bang Nga, về cơ bản, có thuộc tính hiến pháp pháp quyền và trên cơ sở đó nước Nga thiết lập nền dân chủ đa nguyên,

\footnotetext{
"Tác giả liên hệ.

Địa chi email: thangmv@vnu.edu.vn

https://doi.org/10.25073/2588-1167/vnuls.4330
}

phân quyền và hệ thống pháp luật tương đối đồng bộ, hiện đại. Từ các nguyên tắc chung như phân quyền, kiểm soát quyền lực, độc lập tư pháp, chủ quyền nhân dân, quyền con người, tự quản địa phương đến các nguyên tắc, quy định cụ thể như "suy đoán vô tội", "luật bất hồi tố", "tố tụng tranh tụng", "bình đẳng trước luật pháp và tòa án", “được xét xử bởi một tòa án có thẩm quyền, vô tư, khách quan và kịp thời", "quyền được xét xử phúc thẩm", "quyền được bồi thường", ... đều đã được ghi nhận đầy đủ và dần hiện thực hóa trong đời sống chính trị - pháp luật.

Điều chứng minh sự hiện hữu của "trình tự pháp luật công bằng” trong luật pháp nước Nga.

Như vậy, với một nguyên tắc được hình thành, phát triển ở Thông luật vốn có nhiều điều khác biệt, "trình tự pháp luật công bằng" được nhận thức, thể hiện như thế nào ở một hệ thống pháp luật đang bước ra từ truyền thống Xô Viết và phát triển theo các giá trị, chuẩn mực của hệ thống pháp luật châu Âu lục địa nhưng vần mang trong mình đầy đủ sự đa dạng và nhiều khi là "hỗn tạp" vốn có của một nền văn hóa pháp luật được cho là có sự pha trộn, giằng co 
giữa châu Á và châu Âu, giữa phương Đông và phương Tây [3], giữa pháp luật XHCN và châu Âu lục địa, thậm chí có cả bóng dáng của truyền thống pháp luật Á Đông, Luật Hồi giáo,... chắc chắn sẽ có nhiều điều cần được nghiên cứu, làm rõ để từ đó có những liên hệ tới Việt Nam trong điều kiện đẩy mạnh xây dựng nhà nước pháp quyền và hội nhập như hiện nay.

\section{Nhận thức về "trình tự pháp luật công bằng" ở Liên bang Nga}

Hệ thống pháp luật Nga hiện nay có nhiều dấu ấn tư tưởng, quan điểm của các học giả ÂuMỹ bởi khi bắt đầu tiến hành cải cách pháp luật và xây dựng hiến pháp của chế độ mới vào đầu những năm 1990, người Nga đã mời nhiều chuyên gia đến từ các quốc gia này. Dù vậy, "due process of law" với tư cách là một học thuyết hay một nguyên tắc pháp luật căn bản lại không được thể hiện chính thức trong luật pháp. Hiến pháp Liên bang năm 1993 không sử dụng thuật ngữ "due process".

Tới năm 1998, Tòa án Hiến pháp Liên bang trong Quyết định về vụ việc kiểm tra tính hợp hiến của Điều 266 Bộ luật Hải quan Liên bang và Khoản 2 Điều 85 và Điều 222 Bộ luật về Xử lý vi phạm hành chính của Liên bang Nga liên quan đển khiếu kiện của công dân M.M Gagloeva và công dân A.B. Petryakova, lần đầu tiên đã sử dụng thuật ngữ "надлежащая правовая процедура" ("quy trình pháp luật chuẩn”) và thuật ngữ “надлежащая судебная процедура" (“quy trình tư pháp/xét xử chuẩn") [4]. Như vậy, đây là lần đầu tiên thuật ngữ "due process" được chuyển tự và đưa vào văn bản chính thống của $\mathrm{Nga}^{2}$ thông qua thực tiễn xét xử của cơ quan tài phán hiến pháp cao nhất [5].

\footnotetext{
1 Thuật ngữ “надлежащая" ngoài nghĩa “chuẩn”còn có nghĩa là hợp pháp, hợp lý, chuẩn chỉnh, đúng đắn. ${ }^{2}$ Bởi các quyết định của Tòa án Hiến pháp Liên bang Nga thường tạo ra quan điểm pháp lý mới nên có ý nghĩa như là một nguồn luật dạng án lệ kiểu Nga và có giá trị pháp lý rất cao trong hệ thống pháp luật Liên bang Nga.
}

Trong lĩnh vực học thuật, thuật ngữ “надлежащая правовая процедура" (quy trình pháp luật chuẩn) cũng được dùng nhưng không thật sự phổ biến. Các tác giả dùng thuật ngữ này để diễn đạt hay chính xác hơn là dịch lại thuật ngữ "due process of law" trong hệ thống pháp luật Anh -Mỹ sang tiếng Nga. Một số bài viết sử dụng thuật ngữ "надлежащая правовая процедура" (quy trình pháp luật chuẩn) nhưng để trong ngoặc đơn từ gốc tiếng Anh "due process" bên cạnh để biểu đạt sự tương đương [6]. Cách trình bày và diễn giải tương tự cũng bắt gặp ở hầu hết các bài viết liên quan đến vấn đề này cũng như trong các trang thông tin điện tử, các từ điển trực tuyến của Nga hiện nay [7].

Ngoài thuật ngữ "надлежащая правовая процедура" (quy trình pháp luật chuẩn), trong ngôn ngữ và khoa học pháp lý Nga đôi khi cũng dùng thuật ngữ "должная правовая процедура" hay ngắn gọn hơn là "должная процедура" ("quy trình pháp luật cần/phải có" hay "quy trình cần thiết") [8]. Nhưng, thuật ngữ này ít được sử dụng hơn "надлежащая правовая процедура" (quy trình pháp luật chuẩn) để biểu đạt ý nghĩa của "due process".

Ở một bài viết đáng chú ý của mình về cách thức mà Tòa án Hiến pháp Liên bang sử dụng để xử lý các lỗ hổng của pháp luật trong thực tiễn và vai trò của các nguyên tắc pháp luật chung trong quá trình khỏa lấp các lỗ hổng pháp lý, Chánh án Tòa án Hiến pháp Liên bang Nga Zorkin V.D cho rằng nguyên tắc “надлежащая правовая процедура" (quy trình pháp luật chuẩn) là tiêu chí đánh giá tính hợp pháp (bôi đen - TG) của các hành vi tố tụng và tính hợp pháp của các đạo luật quy định các hành vi đó ${ }^{3}$.

\footnotetext{
$\overline{3}$ Về tính hợp pháp: Cần phải giải thích thêm về quan điểm của vị Chánh án này cũng giống như rất nhiều nhà khoa học ở Nga: Ông phân biệt rõ sự khác biệt giữa đạo luật (act), bộ luật (code) và luật (law). Theo đó, các bộ luật, đạo luật hay các văn bản chưa đựng các chuẩn mực phải phù hợp với luật (law - lẽ phải, công bằng, hợp lý,...). Vì vậy, ý nghĩa đoạn trên trong bài phát biểu của ông nằm ở thuật ngữ "tiêu chí của tính hợp pháp" có nghĩa là tiêu chí đánh giá xem các hành vi tố tụng được quy định
} 
Như vậy, thuật ngũ “надлежащая правовая процедура" (quy trình pháp luật chuẩn) dù được dùng nhưng khá hiếm. Nhưng cách dùng từ như vậy để biểu đạt "due process" lại khá xa lạ với nhận thức, tư duy, hoạt động lập pháp, học thuật và thực tiễn pháp luật nước Nga.

Vậy, người Nga đã dùng những thuật ngũ nào để thay thế cho nội hàm "due process"?

Nghiên cứu hệ thống pháp luật, các quan điểm học thuật và thực tiễn tư pháp, không khó để nhận thấy người Nga, ở một mức độ khá phổ biến, thường dùng các thuật ngữ như "Юридическая процедура" (quy trình/thủ tục pháp luật) hoặc "Правовые гарантии” (сác bảo đảm pháp lý) [9]. Đây là các thuật ngữ phù hợp với văn hóa pháp luật Nga hơn cả. Theo đó, “Правовые гарантии” (các bảo đảm pháp lý) được hiểu theo nghĩa rộng và bao hàm nội hàm của "due process" theo nghĩa rộng nhất của hệ thống Anh-Mỹ. Ở đây gồm cả những bảo đảm pháp lý nội dung và bảo đảm pháp lý thủ tục nhằm hướng tới mục tiêu cao nhất là bảo đảm công lý, các quyền và tự do cơ bản của con người, giới hạn và kiểm soát quyền lực nhà nước. Đó cũng là các bảo đảm cho nền tảng pháp quyền và chủ quyền nhân dân. Còn thuật ngữ "Юридическая процедура" (quy trình/thủ tục pháp luật) được sử dụng ở nghĩa hẹp hơn, nhấn mạnh đến các quy trình, thủ tục để đạt tới công lý tự nhiên, bảo đảm các quyền, tự do co bản của con người. Ở đây không chỉ là các quy trình tố tụng với năm loại tố tụng được hiến định gồm: tố tụng hiến pháp, tố tụng dân sự, tố tụng trọng tài (tố tụng kinh tế), tố tụng hành chính và tố tụng hình sự [10], mà còn cả những

trong các văn bản luật (bộ luât, đạo luật...) có phù hợp với luật pháp theo nghĩa luật tự nhiên (law) hay không. Điều này vì những hạn chế của ngôn ngũ tiếng Việt mà rất có thể đã không thể dịch và được hiểu đúng nghĩa và vì vậy cần phải được giải thích thêm dù đây là tư duy phổ biến của pháp luật hiện đại (nguyên nghĩa tiếng Nga: “Принципы надлежащей правой процедуры выступают критерием правомерности процессуальных действий и регламентирующих их законов”). quy trình, thủ tục khác nằm ngoài phạm vi của các hình thức tố tụng đó.

Như vậy, pháp luật Nga có sử dụng thuật ngữ của mình để biểu đạt "due process", nhưng không được biểu thị phổ biến trong văn bản chính thống cũng như trong giới học thuật nước này. Thay vào đó, người Nga sử dụng nhiều hơn các thuật ngữ vốn quen thuộc và phù hợp với mình, trong đó phổ biến hơn cả là các thuật ngữ "bảo đảm pháp lŷ̃" và "thủ tục pháp luật" mà nội hàm của nó vẫn hàm chứa nội dung và tinh thần của "due process of law".

\section{Nội dung co bản của trình tự công bằng/bảo đảm pháp lý trong pháp luật Nga hiện nay}

Để làm rõ nội hàm, dưới đây, tác giả sẽ phân tích "trình tự công bằng" ở Nga theo nghĩa hẹp, bởi việc phân tích theo nghĩa rộng (theo nghĩa bảo đảm pháp lý) thì nội hàm sẽ vô cùng rộng và vượt quá phạm vi của "trình tự pháp luật công bằng" "due process of law" trong Thông luật. "Trình tự pháp luật công bằng" ở Liên bang Nga thể hiện ở những nội dung cốt lõi sau:

Thư nhất, trình tự pháp luật công bằng được thể hiện ở một bản Hiến pháp pháp quyền dân chủ, có vị trí tối thượng, được bảo vệ bởi một cơ chế bảo hiến độc lập, chuyên nghiệp và quyền lực.

Hiến pháp Liên bang Nga là luật cơ bản, có hiệu lực trực tiếp, là một bản hiến pháp pháp quyền, dân chủ được thông qua bằng phúc quyết toàn dân. Việc sửa đổi hoặc ban hành hiến pháp được quy định rất chặt chẽ. Theo đó, Quốc hội Liên bang (lưỡng viện) không thể sửa, đồi các chương: Chương 1 "Nền tảng của chế độ hiến pháp"; Chương 2 "Các quyền và tự do cơ bản của con người, của công dân" và Chương 9: "Sửa đổi, bổ sung và xem xét lại Hiến pháp". Nếu muốn xem lại ba chương này, thì cần có sự ủng hộ của $3 / 5$ trên tổng số đại biểu của cả hai viện Liên bang. Trong trường hợp đạt được số phiếu này thì bước tiếp theo là phải thành lập Quốc hội lập hiến để quyết định: 1) giữ nguyên các chương này, không thay đổi, 
hoặc 2) soạn thảo Hiến pháp mới. Nếu câu hỏi thứ hai được Quốc hội lập hiến thông qua thì phải xây dựng Dự thảo Hiến pháp mới và đưa ra toàn dân phúc quyết. Hiến pháp mới chỉ được thông qua nếu thỏa mãn hai điều kiện: 1) phải được trên $50 \%$ phiếu đồng ý trên tổng số cử tri tham gia bỏ phiếu; 2) số cử tri tham gia bỏ phiếu phải đạt hơn $50 \%$ tổng số cử tri có quyền bỏ phiếu [11].

Đối với các chương còn lại (từ chương 3 tới chương 8), Hiến pháp cho phép sửa đổi, bổ sung theo trình tự sửa đổi, bổ sung và ban hành luật hiến pháp Liên bang. ${ }^{4}$ Theo đó, các đề nghị sửa đổi, bổ sung sẽ được thông qua nếu đạt $3 / 4$ tổng số phiếu của các thượng nghị sĩ của Hội đồng Liên bang tán thành và đạt được $2 / 3$ số phiếu của các nghị sĩ của Viện Đu-ma Quốc gia Nga tán thành [12]. Hiến pháp 1993 hiện hành cũng được thông qua bằng phúc quyết toàn dân.

Hiến pháp quy định rõ nguyên tắc dân chủ, nền tảng pháp quyền. Điều 1 khẳng định: "Liên bang Nga là một nhà nước dân chủ pháp quyền liên bang với hình thức chính thể cộng hòa"; Điều 2 "Con người, quyền và tự do của họ là giá trị cao quý nhất. Công nhận, tuân thủ và bảo vệ các quyền, tự do của con người, công dân là nghĩa vụ của nhà nước"; Điều 3 "Chủ thể nắm giữ chủ quyền và là nguồn gốc duy nhất của quyền lực ở Nga là nhân dân đa sắc tộc Liên bang Nga". Hiến pháp Liên bang Nga có hiệu lực pháp lý cao nhất, có hiệu lực trực tiếp và được áp dụng trên toàn lãnh thổ Liên bang. Luật và các văn bản pháp luật khác được ban hành ở Liên bang Nga không được trái với Hiến pháp Liên bang (Điều 15).

Hiến pháp được bảo vệ không chỉ bởi một quy trình sửa đổi, bổ sung chặt chẽ, thông qua bởi toàn dân đối với những nội dung căn bản nhất, một chế độ pháp quyền, xã hội đa nguyên mà còn có được một công cụ bảo vệ chuyên

\footnotetext{
${ }^{4}$ Luật Hiến pháp là các đạo luật được ban hành theo các nội dung được Hiến pháp giao trực tiếp và có hiệu lực pháp lý dưới Hiến pháp nhưng cao hơn tất cả các đạo luật, bộ luật Liên bang khác. Việc sửa đổi các luật này khắt khe và tỉ lệ phiếu thông qua khó khăn hơn rất nhiều so với việc thông qua các luật liên bang thường khác.
}

nghiệp, có quyền uy - Tòa án Hiến pháp Liên bang.

Theo những sửa đổi mới nhất [13], Tòa án Hiến pháp Liên bang là cơ quan tư pháp cao nhất có chức năng giám sát hiến pháp ở Liên bang Nga, thực hiện quyền tư pháp thông qua tố tụng hiến pháp nhằm bảo vệ nền tảng của trật tự hiến pháp, các quyền và tự do cơ bản của con người và công dân, đảm bảo tính tối cao và hiệu lực trực tiếp của Hiến pháp Liên bang trên toàn lãnh thổ Liên bang Nga.

Tòa án Hiến pháp Liên bang có 11 thẩm phán và các thẩm phán được bổ nhiệm bởi Hội đồng Liên bang (Thượng viện) theo đề nghị của Tổng thống.

Thẩm quyền của Tòa án Hiến pháp Liên bang rất rộng, bao gồm cả quyền thụ động thực hiện chức năng bảo hiến theo yêu cầu cửa cơ quan, cá nhân có thẩm quyền, đồng thời cũng có quyền chủ động khi giải quyết các vụ việc cụ thể liên quan đến khiếu kiện của người dân. Ngoài hậu kiểm, Tòa án Hiến pháp còn tiền kiểm (kiểm tra văn bản chưa có hiệu lực pháp luật) để bảo vệ hiến pháp. Luật pháp Nga không chỉ trao thẩm quyền kiểm tra các đạo luật/dự luật và văn bản dưới luật mà còn trao quyền kiểm tra tính hợp hiến đối với những sửa đổi, bổ sung chính bản Hiến pháp 1993 (đối với các sửa đổi, bổ sung các quy định trong chương 3 đến chương 8 của Hiến pháp mà thôi). Không chỉ trao quyền kiểm tra tính hợp hiến các văn bản nội luật, Hiến pháp sửa đổi còn trao quyền kiểm tra cả các điều ước quốc tế chưa có hiệu lực pháp luật, khả năng thi hành các phán quyết của các thiết chế tài phán quốc tế/nước ngoài cũng như các dự luật của cấp chủ thể liên bang.... Để bảo đảm cho hiệu lực của các quyết định của Tòa án Hiến pháp Liên bang, Hiến pháp đã trao thêm quyền cho hoạt động giải thích hiến pháp của thiết chế này. Theo đó, điều ước quốc tế hoặc các quy định nào đó của điều ước quốc tế khi áp dụng vào vụ việc cụ thể đã được Tòa án này giải thích và tuyên là không phù hợp với nội dung của hiến pháp thì chấm dứt hiệu lực. Các văn bản áp dụng điều ước quốc tế đã được giải thích là không phù hợp với hiến pháp thì không được áp dụng [14]. 
Rõ ràng, việc mở rộng thẩm quyền của Tòa án Hiến pháp Liên bang Nga là một tín hiệu tích cực cho thấy Hiến pháp được bảo vệ rất đa diện và tương đối nghiêm ngặt. Bảo vệ hiến pháp bởi một thiết chế độc lập, có chuyên môn sâu rõ ràng là một quy trình chuẩn để qua đó bảo vệ được nền tảng của chế độ hiến pháp, bảo vệ các giá trị pháp quyền và quyền, tự do cơ bản của con người. Điều này cũng truyền tải thông điệp rất rõ là luật pháp Liên bang Nga không chỉ đặt ra các quy trình chuẩn/ trình tự công bằng cho hành pháp và tư pháp để qua đó bảo vệ quyền con người, công lý xã hội mà quy trình/thủ tục công bằng còn được thiết lập cả với cơ quan lập pháp. Theo đó, cơ quan lập pháp liên bang khó có thể tùy tiện ban hành những đạo luật trái hiến pháp, xâm phạm nền tảng pháp quyền, dân chủ đã được hiến định.

Như đã đề cập, khác với nhiều hiến pháp trên thế giới, nước Nga đặt chế độ bảo vệ hiến pháp ở nhiều cấp độ, mức độ khác nhau. Ở cấp độ thứ nhất, hiến pháp không thể sửa đổi và nếu định sửa đổi, bổ sung các quy định đó thì chỉ có thể thực hiện thủ tục làm mới hiến pháp. Ở cấp độ thứ hai, hiến pháp có thể sửa đổi, bổ sung với quy trình khắt khe bằng thủ tục tương tự ban hành luật hiến pháp nhưng phải được kiểm tra bởi Tòa án Hiến pháp. Ở mức độ thứ ba, các luật, dự luật, điều ước quốc tế chưa có hiệu lực, các thỏa thuận, các dự luật của cấp chủ thể liên bang,... đều phải được kiểm tra tính hợp hiến bằng cơ chế tiền kiểm hoặc hậu kiểm, bằng cơ chế chủ động, thụ động của Tòa án Hiến pháp. Và cuối cùng, hiến pháp được bảo vệ bởi một loạt các cơ chế giám sát, phản biện xã hội, quyền dân chủ của người dân,... như nền chính trị đa nguyên, tự do tư tưởng, xã hội dân sự, bầu cử tự do, tự quản địa phương, tự do ngôn luận, tự do hiệp hội,...

Thứ hai, công nhận, tuân thủ và bảo vệ các quyền, tự do của con người, của công dân và xây dựng cơ chế minh bạch giới hạn quyền, tự do của con người, công dân.

Điều 2 Hiến pháp Liên bang 1993 quy định: "Quyền, tự do của con người, của công dân là giá trị cao quý nhất. Việc công nhận, tuân thủ và bảo vệ chúng là nghĩa vụ của nhà nước". Tiếp đó, tại Chương 2 quy định: "Tại Nga, các quyền, tự do của con người và công dân được công nhận và bảo đảm theo các nguyên tắc, chuẩn mực được thừa nhận chung của luật pháp quốc tế và phù hợp với Hiến pháp này; Các quyền, tự do cơ bản của con người là bất khả xâm phạm và thuộc về mọi người ngay từ khi sinh ra" (Điều 17); "Các quyền, tự do của con người và công dân được áp dụng trực tiếp. Chúng xác định ý nghĩa, nội dung và việc áp dụng pháp luật, hoạt động của các quyền lập pháp và hành pháp, của tự quản địa phương và được bảo đảm bởi tư pháp" (Điều 18).

Pháp luật khẳng định và bảo đảm mọi người đều bình đẳng trước pháp luật và tòa án; bảo đảm bình đẳng về quyền và tự do của con người, công dân, không phân biệt giới tính, chủng tộc, quốc tịch, ngôn ngữ, xuất xứ, tài sản và địa vị chính thức, nơi cư trú, thái độ đối với tôn giáo, tín ngưỡng, tư cách thành viên của các hiệp hội xã hội và các điều kiện khác. Nghiêm cấm mọi hình thức hạn chế quyền của công dân bởi lý do họ thuộc về một xã hội, chủng tộc, quốc gia, ngôn ngữ hoặc tôn giáo nhất định (Điều 19). Nhà nước bảo đảm việc bảo vệ đối với các quyền, tự do của con người và công dân và mọi người đều có quyền bảo vệ quyền, tự do của mình bằng mọi biện pháp mà pháp luật không cấm. Mọi người có quyền, tiếp cận các cơ quan liên quốc gia để bảo vệ các quyền và tự do của con người nếu tất cả các biện pháp trong nước hiện có đã hết (Điều 45).

Đối với giới hạn quyền, là luật cơ bản có hiệu lực pháp lý cao nhất Hiến pháp quy định: "Các quyền và tự do của con người và công dân chỉ có thể bị giới hạn bởi luật liên bang trong phạm vi cần thiết nhằm bảo vệ nền tảng của chế độ hiến pháp, đạo đức, sức khỏe, quyền và lợi ích hợp pháp của người khác, bảo đảm quốc phòng của đất nước và an ninh quốc gia" (Điều 55); “Trong tình trạng khẩn cấp, để đảm bảo an ninh của công dân và bảo vệ trật tự hiến pháp, theo luật hiến pháp liên bang, các hạn chế nhất định đối với các quyền và tự do có thể được thiết lập với điều kiện chỉ ra các giới hạn và thời hạn có hiệu lực của các biện pháp đó" (Điều 56).

Không phải tất cả các quyền, tự do của con người và công dân đều có thể bị hạn chế. Hiến 
pháp chỉ rõ các quyền sau không thể bị hạn chế, gồm: 1) quyền sống; 2) phẩm giá của cá nhân (cấm các hình thức bức cung, nhục hình và các hình thức khác làm tổn hại phẩm giá của con người và cấm các thí nghiệm y tế, khoa học nếu không có sự đồng ý của chính người đó); 3) quyền bất khả xâm phạm đời tư, bí mật cá nhân và gia đình, quyền bảo vệ nhân phẩm và danh dự của mình; 4) cấm thu thập, lưu giữ, sử dụng và phát tán thông tin đời tư khi không có sự đồng ý của chính người đó và một số quyền khác được quy định trong các điều 34 (khoản 1), 40 Điều (khoản 1 ) và các điều 46 - 54 của Hiến pháp Liên bang.

Đặc biệt, Điều 55 có ghi nhận: "1) Việc liệt kê trong Hiến pháp Liên bang Nga các quyền và tự do cơ bản không nên được hiểu là sự phủ nhận hoặc làm giảm bớt các quyền và tự do của con người và công dân được công nhận rộng rãi. 2) Ở Liên bang Nga, luật không được ban hành nhằm xóa bỏ hoặc làm giảm bớt các quyền và tự do của con người và công dân".

Như vậy, pháp luật đã quy định khá toàn diện, phù hợp với các chuẩn mực quốc tế về quyền con người. Bên cạnh đó, không chỉ là các quy định, Hiến pháp còn thiết lập cơ chế bảo đảm thực thi thông qua: 1 ) cơ chế bảo hiến và giải thích hiến pháp của Tòa án Hiến pháp; 2) hệ thống tòa án; 3) Tổng thống Liên bang với trách nhiệm là người bảo vệ quyền con người, quyền công dân; 4) hệ thống Viện kiểm sát; 5) các thiết chế thanh tra nhân quyền; 5) giám sát xã hội, xã hội dân sự; 6) các thiết chế tài phán quốc tế; 7) các quyền chính trị, dân sự như biểu tình, các bầu cử tự do, tham gia trưng cầu ý dân, khiếu nại, tố cáo,... và nhiều hình thức, phương pháp khác.

Thứ $b a$, pháp luật Liên bang Nga thừa nhận và bảo đảm tuân thủ các nguyên tắc, thủ tục của nền tư pháp pháp quyền, dân chủ, hiện đại.

Hiện ở Nga thiết lập năm loại tố tụng và đều có những nguyên tắc, quy định hướng đến quy trình tố tụng chuẩn, gồm: tố tụng hiến pháp, tố tụng dân sự, tố tụng trọng tài, tố tụng hình sự, tố tụng hành chính. Trong đó, tố tụng hiến pháp là quy trình, thủ tục nhằm "cương tỏa" các cơ quan lập pháp cả cấp bang và liên bang để bảo vệ quyền, tự do của con người khỏi các vi phạm của chính các cơ quan này, các quy trình tố tụng còn lại đều là các loại tố tụng thường. Hệ thống và quy trình tố tụng đồ sộ này cũng là để bảo đảm các quyền, tự do của con người và hiện thực hóa quy định của Hiến pháp "mọi người đều được bảo đảm các quyền, tự do của mình bằng cơ chế bảo vệ tư pháp" (Điều 46).

Ngoài ra, ở Nga đã ghi nhận và áp dụng nhiều nguyên tắc, quy định khác để bảo đảm "quy trình chuẩn". Có thể kể đến như các bảo đảm quyền xét xử chỉ thuộc về tòa án và việc cấm thành lập các tòa án khẩn cấp/các tòa án đặc biệt; các thẩm phán độc lập và chỉ tuân theo Hiến pháp và các luật Liên bang. Thẩm phán không thể bị thay thế và bất khả xâm phạm. Quyền hạn của thẩm phán chỉ có thể bị chấm dứt hoặc bị đình chỉ theo cách thức và những căn cứ do luật liên bang quy định.

Trình tự tố tụng công bằng cũng đã được quy định trong Bộ Luật tố tụng hình sự Liên bang (TTHS) và áp dụng trên thực tế.

Trước hết, ngoài những quy định chung như bảo đảm sự độc lập của thẩm phán, quyền xét xử chỉ thuộc về tòa án, luật tố tụng đã khẳng định và thiết lập cơ chế vận hành các quy định tiến bộ như nguyên tắc suy đoán vô tội, tranh tụng/đối khác trong xét xử, tự do đánh giá chứng cứ, bất khả xâm phạm của mỗi cá nhân, giải quyết vụ án hình sự trong thời hạn hợp lý, quyền được kháng cáo các quyết định của tư pháp, bảo vệ quyền, tự do của con người trong tố tụng hình sự; tôn trọng danh dự và nhân phẩm của các cá nhân [15],...

Có thể lấy ví dụ về nguyên tắc suy đoán vô tội. Theo đó, nguyên tắc này ở Nga được cho là tương thích với suy đoán vô tội như là một cấu phần của "due process" Hoa Kỳ. Theo luật tố tụng hình sự Nga, suy đoán vô tội có nội hàm gồm: 1) Người bị buộc tội được coi là người không có tội cho đến khi nào tội của anh ta vẫn chưa được chứng minh theo trình tự được quy định bởi Bộ luật TTHS Liên bang Nga và chưa được tuyên là có tội bởi một bản án kết tội của tòa án đã có hiệu lực pháp luật; 2) Nghi phạm hoặc bị can, bị cáo không có nghĩa vụ chứng minh mình vô tội. Nghĩa vụ chứng minh cho bản luận tội và bác bỏ những lập luận được đưa 
ra để bào chữa cho nghi phạm, bị can hoặc bị cáo thuộc về bên buộc tội; 3) Tất cả nghi ngờ về việc phạm tội của bị cáo nếu không thể được loại bỏ theo thủ tục được thiết lập bởi Bộ luật TTHS Liên bang Nga thì đều được giải thích có lợi cho bị cáo; 4) Một bản án kết tội không thể dựa trên các giả định [16].

Không gọi tên là "tố tụng tranh tụng", nhưng luật TTHS Nga ghi nhận nguyên tắc bảo đảm "Tính đối kháng của các bên"5. Nội hàm nguyên tắc này trong TTHS Nga là: 1) TTHS được thực hiện trên cơ sở đối kháng của các bên; 2) Các chức năng khởi tố, bào chữa, giải quyết vụ án hình sự phải biệt lập với nhau và không thể được giao cho cùng một cơ quan hoặc cùng một người; 3) Tòa án không phải là cơ quan truy tố, điều tra hình sự, không đứng về bên công tố hay bên bào chữa. Tòa án tạo các điều kiện cần thiết để các bên thực hiện nghĩa vụ tố tụng và các quyền đã được pháp luật trao cho họ; 4) Bên luận tội và bên bào chữa bình đẳng trước toà án [17].

Như vậy, ở Nga dù được đặt tên có khác một chút, nhưng nội hàm của nguyên tắc này được bảo đảm tương thích với tố tụng tranh tụng ở phương Tây.

Ngoài những quy định trên, luật TTHS Nga bảo đảm quyền được sử dụng bồi thẩm đoàn của bị can, bị cáo đối với các trường hợp luật định. Quyền được xét xử phúc thẩm, giám đốc thẩm và tái thẩm được bảo đảm.

Tố tụng dân sự Liên bang Nga cũng hàm chứa tương đối đầy đủ các nội dung, yêu cầu của trình tự công bằng. Quyền tiếp cận tòa án, quyền tự quyết của đương sự, bình đẳng các bên trong tố tụng, tranh tụng trong xét xử, xét xử kịp thời, công khai trong xét xử...được ghi nhận và bảo đảm.

Đối với thủ tục hành chính và tố tụng hành chính, có thể nói, cùng với quá trình xây dựng nhà nước pháp quyền, các thủ tục này cũng có nhiều chuyển biến theo hướng bảo đảm trình tự, thủ tục công bằng và bảo đảm quyền, tự do của con người. Trước đây, trong thời kỳ Xô Viết,

\footnotetext{
${ }^{5}$ Nguyên văn tiếng Nga là: “Состязательность сторон” (Tính đối kháng của các bên).
}

hầu hết các vi phạm hành chính được xử lý bởi các chủ thể quản lý nhà nước. Kể từ năm 2001, Bộ luật xử lý vi phạm hành chính Liên bang được ban hành, trình tự công bằng hơn đã được thể hiện. Nhưng, khác với nhiều quốc gia, Bộ luật này thiết lập hai loại thủ tục: 1) thủ tục dành cho tòa án (tố tụng hành chính); và 2) thủ tục dành cho các chủ thể khác. Trong đó, thủ tục tư pháp (tố tụng hành chính) có nhiều quy định, nguyên tắc tương thích với các loại tố tụng khác và đều thể hiện được trình tự tố tụng công bằng.

Trước hết, ngoại trừ hình thức cảnh cáo và phạt tiền, đại đa số các chế tài hành chính được quy định trong Bộ luật này đều đã được được áp dụng bởi thẩm phán - theo thủ tục tư pháp chứ không phải theo thủ tục hành chính như trước đây.

Nguyên tắc suy đoán vô tội cũng được ghi nhận và bảo đảm trong tố tụng hành chính ở Liên bang Nga. Tại Điều số 1.5 quy định: "1) Một người chỉ phải chịu trách nhiệm hành chính về những hành vi vi phạm hành chính mà lỗi của hành vi đó đã được khẳng định; 2) Khi thủ tục tố tụng của một vụ án hành chính đang tiến hành với một cá nhân/tổ chức thì cá nhân/tổ chức đó được coi là không có tội cho đến khi tội của họ được chứng minh theo thủ tục do Bộ luật quy định và được khẳng định trong quyết định của thẩm phán, cơ quan hoặc người có chức vụ thẩm quyền đang thụ lý vụ án; 3) Một người bị xử lý trách nhiệm hành chính không có nghĩa vụ phải chứng minh mình vô tội, trừ những trường hợp được loại trừ trong phụ lục của điều này; 4) Những nghi ngờ không thể khỏa lấp đối với lỗi của người đang bị truy cứu trách nhiệm hành chính thì được diễn giải theo hướng có lợi cho người đó"[18]. Phụ lục của quy định này quy định danh mục các hành vi được loại trừ khỏi nghĩa vụ chứng minh gồm những vi phạm liên quan đến lãnh thổ, vi phạm về lĩnh vực bất động sản và những hành vi mà luật cho phép sử dụng các phương tiện kỹ thuật để lưu giữ chứng cứ bằng camera, video,... (các vi phạm trong lĩnh vực giao thông, quản lý trật tự đô thị).

Ngoài các bảo đảm trên, luật xử lý vi phạm hành chính thiết kế các quy trình, thủ 
tục rất chi tiết cho việc xử lý từng loại hành vi vi phạm hành chính. Pháp luật ghi nhận và bảo đảm thực thi các nguyên tắc bình đẳng trước pháp luật, quyền được xét xử, giải quyết vụ án trong thời hạn hợp lý, bảo đảm pháp chế trong xử lý vi phạm hành chính, bảo đảm quyền bào chữa, trợ giúp pháp lý, quyền kháng cáo, khiếu nại của người bị xử lý vi phạm hành chính, quyền được xem xét vụ việc ở cấp phúc thẩm và xem xét lại vụ việc theo thủ tục giám đốc thẩm và tái thẩm,...

Bên cạnh các thủ tục giải quyết vụ án vi phạm hành chính, luật này còn quy định cả trình tự thủ tục thi hành các quyết định giải quyết vi phạm hành chính ứng với mỗi loại chế tài cụ thể được ấn định trong quyết định đó. Điều này lại không được chứng kiến trong luật TTHS Nga. Thiết nghĩ, quy trình chuẩn, thủ tục chặt chẽ và công bằng không nên chỉ dừng lại ở quy trình điều tra, truy tố, xét xử mà phải còn bao gồm cả quy trình tổ chức thực thi các bản án, quyết định của tòa án - giai đoạn thi hành án hình sự. Trong quá trình thụ án hay tổ chức thực hiện các bản án, quyết định tư pháp luôn tiềm ẩn nhiều rủi ro vì ở đó có thể nảy sinh nhiều vấn đề, ảnh hưởng thậm chí xâm hại đến quyền, an ninh cá nhân, nhân phẩm, danh dự của người đang thụ án. Nước Nga đã ban hành riêng Bộ luật Thi hành án hình sự. Dù mục tiêu chung của bộ luật này cũng không khác nhiều so với bộ luật TTHS, nhưng các bảo đảm pháp lý, các nguyên tắc của bộ luật TTHS lại không thể dùng cho bộ luật thi hành án hình sự. Điều đáng nói là các nguyên tắc, bảo đảm pháp lý trong TTHS Nga được cho là khá tương thích với "due process of law", nhưng các nguyên tắc, nội dung của bộ luật thi hành án hình sự lại không được như vậy. Đây cũng là vấn đề cần phải được xem xét vì thủ tục xét xử có công bằng, nhưng nếu quá trình sau đó quyền, an ninh con người không được bảo đảm thì mọi "trình tự pháp luật công bằng" cũng không còn nhiều ý nghĩa. Điều này cũng cần được xem xét trong bối cảnh Việt Nam hiện nay.

Như vậy, có thể khẳng định, thuật ngữ "due process of law" không được sử dụng phổ biến ở Nga nhưng nội hàm của nó được thể hiện khá đầy đủ trong đời sống pháp luật quốc gia này. Điều này không đến từ văn hóa, truyền thống pháp luật của Nga mà đến từ quá trình dân chủ hóa đời sống xã hội và nhà nước, xây dựng nhà nước pháp quyền và hội nhập quốc tế của nước Nga sau khi Liên Xô sụp đổ. Thủ tục pháp luật công bằng ở nghĩa hẹp hay bảo đảm pháp lý theo nghĩa rộng được sử dụng phổ biến hơn cả ở Nga để biểu đạt nội hàm của "due process of law" của quốc gia này. Các bảo đảm quan trọng nhất đến từ xây dựng nhà nước pháp quyền, xã hội dân sự, bảo đảm quyền, tự do, danh dự và phẩm giá của con người, các bảo đảm khác được thể hiện khá chi tiết ở các nguyên tắc, quy định và các cơ chế bảo hiến, các quy trình tố tụng trong các loại tố tụng được thừa nhận ở Nga hiện nay. Dù vậy, có thể khẳng định, những bảo đảm pháp lý hay các thủ tục/trình tự dù có công bằng đến mấy thì vẫn cần một hệ sinh thái phù hợp. Tác giả muốn nói đến năng lực làm chủ của người dân, trình độ dân trí và kinh tế, văn hóa chính trị cởi mở, một xã hội dân sự phát triển, tính mở và hội nhập của xã hội. Đó cũng là các yếu tố khác để giúp các quy trình/thủ tục công bằng được bảo đảm và đạt được mục tiêu, ý nghĩa trên thực tế.

\section{Lời cảm ơn}

Nghiên cứu này được tài trợ bởi Quỹ Phát triển khoa học và công nghệ Quốc gia (NAFOSTED) trong đề tài mã số 505.012018.300.

\section{Tài liệu tham khảo}

[1] Bùi Tiến Đạt, Học thuyết trình tự công bằng và việc bảo vệ quyền con người: Kinh nghiệm quốc tế và Việt Nam. Tạp chí Nghiên cứu Lập pháp Số 11 (291) T6/2015.

[2] Điều 1 Hiến pháp Liên bang Nga năm 1993.

[3] Mai Văn Thắng, Văn hóa pháp luật nước Nga những đặc trưng cơ bản, Trong Sách chuyên khảo "Văn hóa pháp luật: Những vấn đề lý luận cơ bản và ứng dụng chuyên ngành", Chủ biên GS.TS. 
Hoàng thị Kim Quế, TS. Ngô Huy Cương. NXB. ĐHQGHN, 2011.

[4] Quyết định của Tòa án Hiến pháp Liên bang Nga năm 1998 về vụ việc kiểm tra tính hợp hiến của Điều 266 Bộ luật Hải quan Liên bang Nga và Khoản 2 Điều 85 và Điều 222 Bộ luật về Xử lý vi phạm hành chính của Liên bang Nga liên quan đến khiếu kiện của công dân Gagloeva M.M và công dân Petryakova A.B. Xem tại: https://legalacts.ru/doc/postanovleniekonstitutsionnogo-suda-rf-ot-11031998-n/.

[5] Bài viết của tác giả S.D. Afanasieva, Bảo đảm tuân thủ nguyên tắc trình tự pháp luật chuẩn trong việc thu hồi đất vì mục đích công cộng: kinh nghiệm nước Nga" trong Kỷ yếu hội thảo quốc tế "Những vấn đề và triển vọng của pháp luật hiện đại" được tổ chức bởi Trung tâm nghiên cứu Aeterna, Ufa, Liên bang Nga, năm 2015, trang 8 .

[6] Thủ tục công bằng trong việc luận tội Tổng thống Braxin. Tạp chí khoa học của Trường Đại học Tổng hợp Voronezh, số 4, 2018. Xem tại: http://www.vestnik.vsu.ru/pdf/pravo/2018/04/201 8-04-04.pdf.

[7] Xem tại đây:

https://www.krugosvet.ru/enc/ekonomika-ipravo/nadlezhashchaya-pravovaya-protsedura; https://ru.qwe.wiki/wiki/Due_Process_Clause.

[8] Có thể xem ở đây:

https://dic.academic.ru/dic.nsf/lower/14574 https://cyberleninka.ru/article/n/dolzhnaya- pravovaya-protsedura-i-pravovye-standartyevropeyskogo-suda-po-pravam-cheloveka/viewer: https://studopedia.ru/10_234679_dolzhnayaprotsedura.html.

[9] http://law.edu.ru/book/book.asp?bookID=1451703;

[10] Khoản 2 Điều 118 Hiến pháp Liên bang Nga năm 1993 (sửa đổi, bổ sung năm 2020).

[11] Điều 135 Hiến pháp Liên bang Nga năm 1993.

[12] Điều 108 Hiến pháp Liên bang Nga năm 1993.

[13] Khoản 1Điều 125 của Hiến pháp sửa đổi năm 2020.

[14] Khoản 6, Điều 125 Hiến pháp Liên bang Nga bổ sung 2020.

[15] Chương 2 Bộ Luât Tố tụng Hình sự Nga: http://base.garant.ru/12125178/20277f96087c78b 2a677d1634ba5be1c/.

[16] Điều 14, Bộ Luật Tố tụng Hình sự Nga: http://base.garant.ru/12125178/53f89421bbdaf741 eb2d1ecc4ddb4c33/.

[17] Điều 15 Bộ luật Tố tụng Hình sự Nga: http://base.garant.ru/12125178/36bfb7176e3e8bfe be 718035887e4efc/.

[18] http://www.consultant.ru/document/cons_doc_LA W_34661/c4e643d138637f4eafb763d628fc44ef99 c71a15/. 